\title{
RESENHA \\ IMAGENS DO PENSAMENTO: SOCIEDADE HIPERCOMPLEXA E EDUCAÇÃO REMOTA
}

\author{
Vinícius Barbosa Cannavô (D)1 e Tainá Suppi Pinto (D)2
}

A resenha tem como referência bibliográfica a seguinte obra:

HABOWSKI, Adilson Cristiano; CONTE, Elaine (Orgs.). Imagens do pensamento: sociedade hipercomplexa e educação remota. São Paulo: Pimenta Cultural, 2020. 686 p.

A obra Imagens do pensamento: sociedade hipercomplexa e educação remota, organizada pelos pesquisadores Adilson Cristiano Habowski e Elaine Conte (2020), é resultado de um conjunto de 29 artigos com o propósito de compreender e produzir sínteses das discussões recentes frente aos desafios conturbados e dilemas do trabalho com a educação remota. Para pensar a atualidade, apresenta reflexões sobre as mudanças urgentes das tecnologias na educação, em suas interfaces e experiências nos processos de ensino e de aprendizagem, encaminhando novas possibilidades acerca dos efeitos da cultura digital.

Desse modo, a obra é composta por debates que aguçam a criatividade em situações e experiências socioeducacionais de diversas partes do Brasil. Os capítulos, de teor crítico e reflexivo, indicam caminhos para pensar a educação, a justiça social e as questões da política educacional da sociedade hipercomplexa que vive a educação remota em toda explosão criativa, entre limites e superações.

A obra inicia-se com o prefácio "A aprendizagem não pode parar" escrito pela pesquisadora Lucia Santaella (2020, p. 20), que deixa evidente a importância do livro "porque desenha e cartografa situações educacionais diferenciadas vividas no contexto brasileiro da pandemia", apresentando reflexões escritas por profissionais da educação que conseguiram "registrar, analisar e avaliar as ações educativas resilientes" em meio ao contexto da pandemia de Covid-19 vivenciada na atualidade.

Na sequência, a obra é apresentada e organizada em 5 cinco partes. A primeira intitula-se "Sociedades contemporâneas hipercomplexas: fake news, pandemia e ensino remoto" e reúne 5 artigos que abordam o fenômeno das Fake News na pandemia e os multiletramentos digitais (HABOWSKI; CONTE, 2020); as arquiteturas pedagógicas no ensino remoto emergencial, os desafios e as inovações (BEHAR et al., 2020); as reinvenções docentes no ensino remoto, suas narrativas e a formação (CARDOSO, 2020); a questão das dialéticas da aprendizagem entre clausura e liberdade (RIBAS; WILSON, 2020); e uma reflexão sobre Agamben, a pandemia e o silêncio nas universidades (SANTOS, 2020).

\footnotetext{
${ }^{1}$ Mestre em Educação pela Universidade Federal do Rio Grande do Sul. E-mail: viniciuscannavo13@gmail.com.

2Sanitarista pela Universidade Federal do Rio Grande do Sul. E-mail:tainasuppi@gmail.com. 
Em seguida é apresentada a segunda parte, intitulada "Tempos de pandemia e o fortalecimento dos laços emocionais", contemplando cinco trabalhos científicos. Inicia-se com o podcast como possibilidade para reduzir os distanciamentos e fortalecer os laços emocionais em tempos de ensino remoto (SILVA; BRASIL, 2020); passando pelo olhar sobre as vivências de ensino remoto e covid-19 no contexto amazônico (COELHO et al., 2020); experiências de professores com o ensino remoto na pandemia da COVID-19 (CATAI; SCHIAVONS, 2020); os desafios e possibilidades da educação durante a pandemia (NASCIMENTO; SANTOS; CERQUEIRA, 2020); até chegar nas problemáticas acerca de professor e aluno no contexto da pandemia de covid19 e o fazer educacional na visão dialógica (DIEDRICH; SANTOS; OLIVEIRA, 2020).

Na terceira parte, "Cenário de carências e vivências: propostas de atuação flutuante", circunscrita por cinco textos, traz reflexões sobre a inclusão digital em tempos de pandemia e a reinvenção da arte de lecionar (SOUSA; CARVALHO; AGUIAR, 2020); a formação de professores em tempo de pandemia e as práticas interdisciplinares com uso de tecnologias (CARRIL et al., 2020); os sentidos da permanência na educação em tempos de pandemia atribuídos por jovens universitárias e o uso das tecnologias (AQUINO et al., 2020); reflexões sobre a Educação Física escolar durante a pandemia e a atuação dos professores (SANTOS; MELO, 2020); e, para finalizar, considerações e reflexões sobre modalidades de ensino em contexto pandêmico (BARRETO; PONTES; MANHÃES, 2020).

Alguns subsídios para a compreensão do "Campo de estudos e improvisos do ensino remoto" são elencados na parte 4 composta por cinco trabalhos. A seção inicia com uma explicação do contexto e dos conflitos da mediação tecnológica na pandemia: uma análise sobre o acesso ao aplicativo SME carioca 2020 (ROSA et al., 2020); trata sobre as ações pedagógicas remotas no enfrentamento da pandemia, os protocolos da Rede Estadual de Mato Grosso do Sul (DAHER; BENITES; BATISTA, 2020); a docência e o ensino remoto, os retratos dos memes da pandemia (GOMES; NUNES, 2020); os impactos da covid-19 na educação na nova morfologia do trabalho docente no Brasil (REZENDE; LIMA, 2020); até chegar nas práticas pedagógicas e representações sociais: questões para o cenário da pandemia e pós-pandemia (LEITE; MOREIRA, 2020).

A quinta e última parte, intitulada "Aprender na (inter)dependência é preciso: sentidos da (im)permanência virtual" expõe a complexidade da temática ilustrada em nove trabalhos.-Agrega conhecimentos e reflexões sobre a responsabilização das mulheres nas atividades remotas dos(as) filhos(as) no Município de Cascavel diante da pandemia do novo coronavírus (SILVEIRA; PARISOTO, 2020); compartilha experiências do cotidiano da educação em tempos de pandemia (LOUREIRO et al., 2020); reflexões sobre os desafios, entraves e possibilidades da possível educação inclusiva durante a pandemia (SOUZA; HABOWSKI, 2020; SILVA et al., 2020); o uso de podcast para o ensino de geografia no período da covid-19: lições para o cenário pós-pandêmico (PIMENTEL; DAMAS, 2020); o currículo na educação básica e os contratempos no ensino com o contexto da pandemia COVID-19 (BARBIERO; SANTOS; 
ALBANO, 2020); uma proposta didático-pedagógica por meio de metodologias ativas no ensino híbrido (MOLIN; OLIZAROSKI; REICHERT, 2020); as práticas pedagógicas e os processos de ensino e de aprendizagem em tempos de pandemia (ALMEIDA, 2020); e encerra com reflexões de como a pandemia mudou nossa rotina para abrigar um caráter mais educativo (SILVA; SOARES; ALMEIDA, 2020).

Como percebe-se, o livro não pretende oferecer respostas acabadas, mas impulsionar pesquisas a respeito do tema em voga e contextualizar ideias de profissionais da educação que buscam esclarecer algumas situações vividas nas práticas com as tecnologias digitais durante a pandemia. $\mathrm{Na}$ atual conjuntura, observa-se um crescimento acelerado de tecnologias diversas, automatismos e a proliferação de evidências sociopolíticas em todos os âmbitos da vida, necessitando de novas formas de linguagem para interpretar os horizontes informacionais e suas mensagens convulsionadas por crises atuais.

Diante das transformações causadas pela pandemia e após a leitura da obra, fica claro que ela se constitui num fenômeno complexo em que foi engendrada, sendo realizada nos diversos âmbitos da vida social e, nesse aspecto, a análise da educação remota permite compreender os processos de luta e de formação das ideias da sociedade hipercomplexa em movimentos sócio-históricos e culturais. O conjunto dos trabalhos reunidos na obra expressam a inquietação e a incompatibilidade das ideias do ensino presencial aos novos arranjos sociais com os impactos da pandemia, repensando a educação remota como meio para resistir à mera reprodução inesperada e exclusão digital que precisa considerar os processos socioeducacionais continuamente mobilizados pelo pensar e agir pedagógico, sempre em transformação.

Por tudo isso, o caráter pedagógico desempenhado pela obra tem no ato de compartilhar conhecimentos e ideias em torno do universo de experiências formativas recentes, a tentativa de conjecturar um possível legado cultural com práticas expressivas de resistência sociocultural, bem como de narrativas recontextualizadas a movimentos comunicacionais que possam orientar esse campo de pesquisas na educação.

Vale destacar que a obra se trata de uma importante contribuição para a área da educação em vista dessa nova realidade instalada no mundo pandêmico, permitindo esboçar novos questionamentos sobre a linguagem tecnológica na forma emergente no campo educacional. Ao leitor que se interessa pelo tema da sociedade hipercomplexa e da educação remota encontrará textos que apoiam a compreensão dos novos desafios contemporâneos, já que os autores apresentam uma análise consistente e bem documentada do fenômeno da educação remota, alicerçada em um amplo conjunto de pensadores e concepções teórico-práticas de respeitado referencial teórico no Brasil.

\section{REFERÊNCIAS}

ALMEIDA, Claudeci de Paula de. As práticas pedagógicas e os processos de ensino e de aprendizagem em tempos de pandemia. In: HABOWSKI, Adilson Cristiano; CONTE, Elaine (Orgs.). Imagens do pensamento: sociedade 
hipercomplexa e educação remota. São Paulo: Pimenta Cultural, 2020. p. 618634.

AQUINO, Daiane Caetano Costa de, et al. Sentidos da permanência na educação em tempos de pandemia atribuídos por jovens universitárias e o uso das tecnologias como ferramenta pedagógica. In: HABOWSKI, Adilson Cristiano; CONTE, Elaine (Orgs.). Imagens do pensamento: sociedade hipercomplexa e educação remota. São Paulo: Pimenta Cultural, 2020. p. 295316.

BARBIERO, Ana Carolina Neumann; SANTOS, Elizandra Daneize dos; ALBANO, Karine. O currículo na educação básica: contratempos no ensino com o contexto da pandemia covid-19. In: HABOWSKI, Adilson Cristiano; CONTE, Elaine (Orgs.). Imagens do pensamento: sociedade hipercomplexa e educação remota. São Paulo: Pimenta Cultural, 2020. p. 576-591.

BARRETO, Luisa Gonçalves; PONTES, Fernanda Leite Trindade Brito; MANHÃES, Mariana Oliveira. Modalidades de ensino em contexto pandêmico: considerações e reflexões. In: HABOWSKI, Adilson Cristiano; CONTE, Elaine (Orgs.). Imagens do pensamento: sociedade hipercomplexa e educação remota. São Paulo: Pimenta Cultural, 2020. p. 336-356.

BEHAR; Patricia Alejandra; SILVA; Ketia Kellen Araújo da; MACHADO, Leticia Rocha Machado; SONEGO, Anna Helena Silveira. Arquiteturas pedagógicas no ensino remoto emergencial: desafios e inovações. In: HABOWSKI, Adilson Cristiano; CONTE, Elaine (Orgs.). Imagens do pensamento: sociedade hipercomplexa e educação remota. São Paulo: Pimenta Cultural, 2020. p. 5377.

CARDOSO, Marcélia Amorim. Reinvenções docentes no ensino remoto: narrativas e formação. In: HABOWSKI, Adilson Cristiano; CONTE, Elaine (Orgs.). Imagens do pensamento: sociedade hipercomplexa e educação remota. São Paulo: Pimenta Cultural, 2020. p. 78-111.

CARRIL, Maria da Graça Pimentel et al. Formação de professores em tempo de pandemia: práticas interdisciplinares com uso de tecnologias. In: HABOWSKI, Adilson Cristiano; CONTE, Elaine (Orgs.). Imagens do pensamento: sociedade hipercomplexa e educação remota. São Paulo: Pimenta Cultural, 2020. p. 274-294.

CATAI, Carla Botteon; SCHIAVON, Kauan Taiar; "Pode não ser a melhor coisa do mundo, mas funciona": experiências de professores com o ensino remoto na pandemia da COVID-19. In: HABOWSKI, Adilson Cristiano; CONTE, Elaine (Orgs.). Imagens do pensamento: sociedade hipercomplexa e educação remota. São Paulo: Pimenta Cultural, 2020. p. 192-213. 
COELHO, Yuri Cavaleiro de Macêdo et. al. COVID-19, ensino remoto e o contexto amazônico: um olhar sobre nossas vivências. In: HABOWSKI, Adilson Cristiano; CONTE, Elaine (Orgs.). Imagens do pensamento: sociedade hipercomplexa e educação remota. São Paulo: Pimenta Cultural, 2020. p. 171191.

DAHER, Hélio Queiroz; BENITES, Rita de Cássia Ribeiro; BATISTA, Silvana Maria. Ações Pedagógicas Remotas no enfrentamento da pandemia: protocolos da Rede Estadual de Mato Grosso do Sul. In: HABOWSKI, Adilson Cristiano; CONTE, Elaine (Orgs.). Imagens do pensamento: sociedade hipercomplexa e educação remota. São Paulo: Pimenta Cultural, 2020. p. 379-397.

DIEDRICH, Marlete Sandra; SANTOS, João Ricardo Fagundes dos; OLIVEIRA, Marina de. O professor e o aluno no contexto da pandemia de COVID-19: o fazer educacional na visão dialógica. In: HABOWSKI, Adilson Cristiano; CONTE, Elaine (Orgs.). Imagens do pensamento: sociedade hipercomplexa e educação remota. São Paulo: Pimenta Cultural, 2020. p. 234-254.

GOMES, Valdete Aparecida Fernandes Moutinho; NUNES, Célia Maria Fernandes. A docência e o ensino remoto: retratos dos memes da pandemia do covid-19. In: HABOWSKI, Adilson Cristiano; CONTE, Elaine (Orgs.). Imagens do pensamento: sociedade hipercomplexa e educação remota. São Paulo: Pimenta Cultural, 2020. p.398-421.

HABOWSKI, Adilson Cristiano; CONTE, Elaine. Fake news, pandemia e os multiletramentos digitais. In: HABOWSKI, Adilson Cristiano; CONTE, Elaine (Orgs.). Imagens do pensamento: sociedade hipercomplexa e educação remota. São Paulo: Pimenta Cultural, 2020. 686 p.

LEITE, Maria Alzira; MOREIRA, Carla Geralda Leite. Práticas pedagógicas e representações sociais: questões para o cenário da pandemia e pós-pandemia. In: HABOWSKI, Adilson Cristiano; CONTE, Elaine (Orgs.). Imagens do pensamento: sociedade hipercomplexa e educação remota. São Paulo: Pimenta Cultural, 2020. p. 446-464.

LOUREIRO, Célia Regina Machado Jannuzzi, et al. Educação em tempos de pandemia: compartilhando experiências do nosso cotidiano. In: HABOWSKI, Adilson Cristiano; CONTE, Elaine (Orgs.). Imagens do pensamento: sociedade hipercomplexa e educação remota. São Paulo: Pimenta Cultural, 2020. p. 487-504.

MOLIN, Beatriz Helena Dal; OLIZAROSKI, Iara Mikal Holland; REICHERT, Cleuza Maria. Novos tempos, novos seres, novos saberes: uma proposta didático-pedagógica por meio de metodologias ativas no ensino híbrido. In: HABOWSKI, Adilson Cristiano; CONTE, Elaine (Orgs.). Imagens do pensamento: sociedade hipercomplexa e educação remota. São Paulo: Pimenta Cultural, 2020. p. 592-617. 
NASCIMENTO, Edna Gama do; SANTOS, Nataly Ferreira Costa dos; CERQUEIRA, Maria Aline Borges Dantas. Educação durante a pandemia: desafios e possibilidades. In: HABOWSKI, Adilson Cristiano; CONTE, Elaine (Orgs.). Imagens do pensamento: sociedade hipercomplexa e educação remota. São Paulo: Pimenta Cultural, 2020. p. 214-233.

PIMENTEL, Carolina Lima; DAMAS, Eduardo Tavares. O uso de Podcast para o ensino de geografia no período da COVID-19: lições para o cenário póspandêmico. In: HABOWSKI, Adilson Cristiano; CONTE, Elaine (Orgs.).

Imagens do pensamento: sociedade hipercomplexa e educação remota. São Paulo: Pimenta Cultural, 2020. p. 557-575.

REZENDE, Paula Junqueira da Silva; LIMA, Antonio Bosco de. Os impactos da COVID-19 na educação na nova morfologia do trabalho docente no Brasil. In: HABOWSKI, Adilson Cristiano; CONTE, Elaine (Orgs.). Imagens do pensamento: sociedade hipercomplexa e educação remota. São Paulo: Pimenta Cultural, 2020. p. 422-445.

RIBAS, Maria Cristina; WILSON, Victoria. Clausura e liberdade: dialéticas da aprendizagem. In: HABOWSKI, Adilson Cristiano; CONTE, Elaine (Orgs.).

Imagens do pensamento: sociedade hipercomplexa e educação remota. São Paulo: Pimenta Cultural, 2020. p. 112-133.

ROSA, Rondon Marques, et.al. Conflitos da mediação tecnológica na pandemia: uma análise sobre o acesso ao aplicativo SME Carioca 2020. In: HABOWSKI, Adilson Cristiano; CONTE, Elaine (Orgs.). Imagens do pensamento: sociedade hipercomplexa e educação remota. São Paulo: Pimenta Cultural, 2020. p. 358-378.

SANTAELLA, Lucia. A aprendizagem não pode parar. In: HABOWSKI, Adilson Cristiano; CONTE, Elaine (Orgs.). Imagens do pensamento: sociedade hipercomplexa e educação remota. São Paulo: Pimenta Cultural, 2020. p. 1723.

SANTOS, André Luiz dos. Agamben, a pandemia e o silêncio nas universidades. In: HABOWSKI, Adilson Cristiano; CONTE, Elaine (Orgs.). Imagens do pensamento: sociedade hipercomplexa e educação remota. São Paulo: Pimenta Cultural, 2020. p. 134-149.

SANTOS, Genildo Pinheiro; MELO, Gislane Ferreira. Educação Física escolar durante a pandemia: como atuam os professores? In: HABOWSKI, Adilson Cristiano; CONTE, Elaine (Orgs.). Imagens do pensamento: sociedade hipercomplexa e educação remota. São Paulo: Pimenta Cultural, 2020. p. 317335. 
SILVA, Aparecido Fernando da. et. al. Educação inclusiva e ensino remoto: entraves e possibilidades. In: HABOWSKI, Adilson Cristiano; CONTE, Elaine (Orgs.). Imagens do pensamento: sociedade hipercomplexa e educação remota. São Paulo: Pimenta Cultural, 2020. p. 533-556.

SILVA, Cliciane Magalhaes da; SOARES, Ana Deuza da Silva; ALMEIDA, Jamilla de Nazaré de Oliveira. O que esperar quando o inesperado acontece? Reflexões de como a pandemia mudou nossa rotina. In: HABOWSKI, Adilson Cristiano; CONTE, Elaine (Orgs.). Imagens do pensamento: sociedade hipercomplexa e educação remota. São Paulo: Pimenta Cultural, 2020. p. 635-653.

SILVA, Fádia Cristina Monteiro de Oliveira; BRASIL, Judivalda da Silva. Podcast: reduzindo distanciamentos, fortalecendo laços emocionais em tempos de ensino remoto. In: HABOWSKI, Adilson Cristiano; CONTE, Elaine (Orgs.). Imagens do pensamento: sociedade hipercomplexa e educação remota. São Paulo: Pimenta Cultural, 2020. p. 151-170.

SILVEIRA, Danielli Maria Neves da; PARISOTO, Dyeniffer Jessica Bezerra. Pandemia do novo coronavírus e educação: responsabilização das mulheres nas atividades remotas dos(as) filhos(as) no município de Cascavel-PR. In: HABOWSKI, Adilson Cristiano; CONTE, Elaine (Orgs.). Imagens do pensamento: sociedade hipercomplexa e educação remota. São Paulo: Pimenta Cultural, 2020. p. 466-486.

SOUSA, Ângela Maria de Aguiar; CARVALHO; Maria de Lourdes Guimarães de; AGUIAR, Maria Simara de. Inclusão digital em tempos de pandemia: reinventando a arte de lecionar. In: HABOWSKI, Adilson Cristiano; CONTE, Elaine (Orgs.). Imagens do pensamento: sociedade hipercomplexa e educação remota. São Paulo: Pimenta Cultural, 2020. p. 256-273.

SOUZA, Mariana Pinkoski de; HABOWSKI, Adilson Cristiano. Reflexões sobre os desafios da possível educação inclusiva durante a pandemia. In: HABOWSKI, Adilson Cristiano; CONTE, Elaine (Orgs.). Imagens do pensamento: sociedade hipercomplexa e educação remota. São Paulo: Pimenta Cultural, 2020. p. 505-532.

Recebido em: 26 de janeiro de 2021. Aceito em: 23 de abril de 2021. Publicado em: 15 de dezembro de 2021. 